\title{
Ação do Extrato de Chá Verde sobre a Geração de Espécies Reativas de Oxigênio (ROS) em Mitocôndrias Isoladas de Fígado de Ratos com Artrite Induzida por Adjuvante
}

\author{
Geferson de Almeida Gonçalves ${ }^{1}$, AnacharisBabeto de Sá-Nakanishi ${ }^{1}$, Jurandir \\ Fernando Comar ${ }^{1}$, Mariana Marques Nogueira Wendt ${ }^{1}$, Caroline Aparecida Vaz de \\ Araújo $^{1}$, Tatiane Brugnari ${ }^{1}$, Camila Gabriel Kato ${ }^{1}$, Rosane Marina Peralta1, Adelar \\ Bracht $^{1}$, \\ ${ }^{1}$ Universidade Estadual de Maringá - Departamento de Bioquímica \\ CEP 87020-900 Maringá - PR - E-mail: (gefersonag@ig.com.br)
}

\begin{abstract}
RESUMO
Animais e pacientes com artrite apresentam considerável estresse oxidativo. $O$ objetivo deste trabalho foi verificar a ação do extrato de chá verde sobre a geração de espécies reativas de oxigênio (ROS) em mitocôndrias isoladas de fígado de ratos com artrite induzida por adjuvante, tendo em vista que a respiração mitocondrial é a principal responsável pela geração de radicais livres no organismo. Foram utilizadas mitocôndrias isoladas de fígado de ratos machos da linhagem Holtzman, divididos em dois grupos, controle e com artrite induzida por adjuvante completo de Freund. Mitocôndrias isoladas de animais artríticos apresentaram maior produção de ROS. $O$ extrato de chá verde diminuiu a produção de ROS tanto de mitocôndrias de animais controle como de animais artríticos, mas tendeu a ter um efeito maior sobre as mitocôndrias de animais artríticos. Estes resultados são compatíveis com as observações prévias acerca do efeito benéfico do chá verde sobre o estresse oxidativo induzido pela artrite.
\end{abstract}

Palavras-chaves: Chá verde, Artrite reumatóide, Mitocôndrias, Fígado de ratos, Espécies reativas de oxigênio (ROS).

\section{INTRODUÇÃO}

O consumo de chá verde e preto pode trazer efeitos positivos para a saúde. Uma hipótese que explica esses efeitos é que os altos níveis de flavonóides do chá podem proteger as células e tecidos de danos oxidativos pela eliminação de radicais livres (RIETVELD \& WISEMAN, 2003).

A atividade antioxidante das catequinas pode prevenir a citotoxicidade induzida pelo estresse oxidativo em diferentes tecidos, pois possui ação sequestrante de radicais livres e ação quelante de metais de transição tais como ferro e cobre. A propriedade antioxidante das catequinas do chá verde tem sido apontada como o principal fator contribuinte na prevenção e/ou no tratamento de diversas doenças crônico-degenerativas incluindo o câncer, doenças cardiovasculares e diabetes mellitus (RIETVELD \& WISEMAN, 2003).

A respiração mitocondrial é a principal responsável pela geração de radicais livres no organismo. Estes radicais se encontram envolvidos na produção de energia, fagocitose, regulação do crescimento celular, sinalização intercelular e síntese de substâncias biológicas importantes. No entanto, seu excesso apresenta efeitos prejudiciais, tais como a peroxidação

Universidade Estadual de Londrina- Rodovia Celso Garcia Cid, Pr445, Km 380 - Campus Universitário Caixa Postal 10.011 CEP 86057-970Centro de Ciências Exatas - Departamento de Bioquímica e BiotecnologiaFone +55 (43) 3371.4270 - biq@uel.br 


\title{
V SIMPÓSIO DE BIOQUÍMICA E BIOTECNOLOGIA
}

\author{
05 a 07 de agosto de 2015, Londrina - PR
}

\section{VSIMBBTEC \\ Londrina 2015}

dos lipídios de membrana e agressão às proteínas dos tecidos e das membranas, às enzimas, carboidratos e DNA (HUSAIN, CILLARD \& CILLARD, 1987).

A artrite reumatóide é uma doença autoimune caracterizada por inflamação crônica e sistêmica que afeta a cartilagem articular, membrana sinovial e ossos. A patologia apresenta uma prevalência de aproximadamente $1 \%$ na população adulta e está associada com um aumento na taxa de mortalidade, principalmente devido a complicações vasculares inflamatórias e caquexia (SENNA et al., 2004; GABRIEL \& MICHAUD, 2009). A artrite induzida pelo adjuvante completo de Freund é uma imunopatologia experimental em ratos que apresenta semelhanças com a artrite reumatóide humana: hiperplasia sinovial, inflamação sistêmica, caquexia e altos níveis de citocinas pró-inflamatórias no plasma e nos sítios de lesão (BENDELE et al., 1999; SZEKANECZ et al., 2000). São observadas também alterações substanciais no estado oxidativo do fígado de ratos artríticos, como por exemplo, níveis mais elevados de ROS, grupos carbonilo de proteínas e substâncias reativas ao ácido tiobarbitúrico (TBARS) (COMAR et al., 2013). Por isto, este modelo tem sido utilizado para a avaliação de drogas antiinflamatórias e antireumáticas. Diante desta situação, é importante traçar novas alternativas terapêuticas para 0 tratamento da doença, incluindo o uso de fitoterápicos como o chá verde. Por isto, o objetivo desse trabalho foi o de verificar a ação do extrato de chá verde (Camellia sinensis) sobre a geração de ROS em mitocôndrias isoladas de fígado de ratos com artrite induzida por adjuvante.

\section{MATERIAL E MÉTODOS}

O chá verde utilizado neste estudo foi adquirido no comércio local (Maringá - PR, Brasil). São folhas de Camellia sinensis var. assamica produzidas no Brasil (Vale do Ribeira), secas, trituradas até textura de pó fino e acondicionadas em caixas com conteúdo designado como chá a granel. O chá foi preparado por infusão (1g de folhas de chá verde seco/100mL de água destilada) a $80{ }^{\circ} \mathrm{C}$ por 8 minutos, sob agitação constante. Após filtração a vácuo, os extratos foram liofilizados e armazenados em freezer até uso.

Foram utilizados ratos machos da linhagem Holtzman fornecidos pelo Biotério Central da Universidade Estadual de Maringá, alimentados ad libitum com ração balanceada (Nuvilab ${ }^{\circledR}$, Colombo, Brasil) e mantidos em um ambiente com controle de temperatura $\left(22 \pm 2^{\circ} \mathrm{C}\right)$ e ciclo claro/escuro (12h/12h). Os animais foram divididos em 2 grupos, mantidos em gaiolas de polietileno com grade de aço, com 4 animais por gaiola.Os grupos foram denominados como controle e artrítico.

A artrite foi induzida em ratos com 50 dias de idade, através da injeção intradérmica na pata traseira esquerda com 0,1 mL de adjuvante completo de Freund (Mycobacterium tuberculosis derivadas de cepa humana H37Rv e inativadas pelo calor, suspensas em óleo mineral 0,5\% $(\mathrm{m} / \mathrm{v})$ ) (PEARSON \& WOOD, 1963).

Após 18 dias da indução da artrite os ratos em jejum $(18 \mathrm{~h})$, foram decapitados e o fígado foi removido cirurgicamente. As mitocôndrias foram obtidas pela homogeneização do fígado em meio de isolamento, seguido de duas centrifugações seqüenciais (8.000 rpm). Após dois ciclos de lavagens, por ressuspensão e recentrifugação do sedimento, as mitocôndrias foram ressuspensas no mesmo meio, até concentração protéica de cerca de 40 a $50 \mathrm{mg} / \mathrm{ml}$. A dosagem de proteínas foi realizada pela técnica descrita por Lowry et al., utilizando albumina bovina como padrão.

Universidade Estadual de Londrina- Rodovia Celso Garcia Cid, Pr445, Km 380 - Campus Universitário Caixa Postal 10.011 CEP 86057-970Centro de Ciências Exatas - Departamento de Bioquímica e BiotecnologiaFone +55 (43) 3371.4270 - biq@uel.br 
O nível de produção de ROS mitocondrial, basicamente peróxido de hidrogênio, foi estimado por mensuração do aumento linear de fluorescência (504nm emissão e $529 \mathrm{~nm}$ excitação) (ZACCAGNINO et al., 2009). $\mathrm{H}_{2} \mathrm{O}_{2}$ induz oxidação da diclorofluoresceína (DCFA-DA) formando um composto fluorescente na presença da enzima peroxidase (HRP). Mitocôndrias intactas ( $\approx 0.8 \mathrm{mg}$ de proteína) foram adicionadas em $2 \mathrm{~mL}$ de tampão Manitol $250 \mathrm{mM}$, Hepes $10 \mathrm{mM}$ pH 7.2 , contendo $1.36 \mu \mathrm{M}$ de DCFA-DA e succinato $(10 \mathrm{mM})+$ rotenona $(10 \mu \mathrm{M})$. A reação foi iniciada pela adição de $0.4 \mu \mathrm{M}$ de HRP, e a fluorescência registrada em intervalo de 1 minuto durante 10 minutos. Todo o ensaio ocorreu sob agitação. Os resultados foram expressos em nmoles de ROS produzido por minuto por miligrama de proteína.

Os resultados foram expressos como média \pm erro padrão. As médias foram submetidas à análise de variância múltipla (MANOVA) e pós-teste Duncan, com nível de significância de $5 \%$ ( $p$ $<0,05)$, utilizando Statistica ${ }^{\circledR}$.

\section{RESULTADOS E DISCUSSÃO}

A geração de ROS foi $60 \%$ maior nas mitocôndrias isoladas de ratos artríticos que nas mitocôndrias dos animais controle (Figura 1). A administração de $0,1 \mathrm{mg} / \mathrm{ml}$ do extrato de chá verde causou uma diminuição maior na geração de ROS (45\%) nas mitocôndrias isoladas de ratos artríticos que nas mitocôndrias isoladas de animais controle (30\%). Administração de doses mais elevadas de extrato de chá diminuiu a geração de ROS de maneira mais discreta.

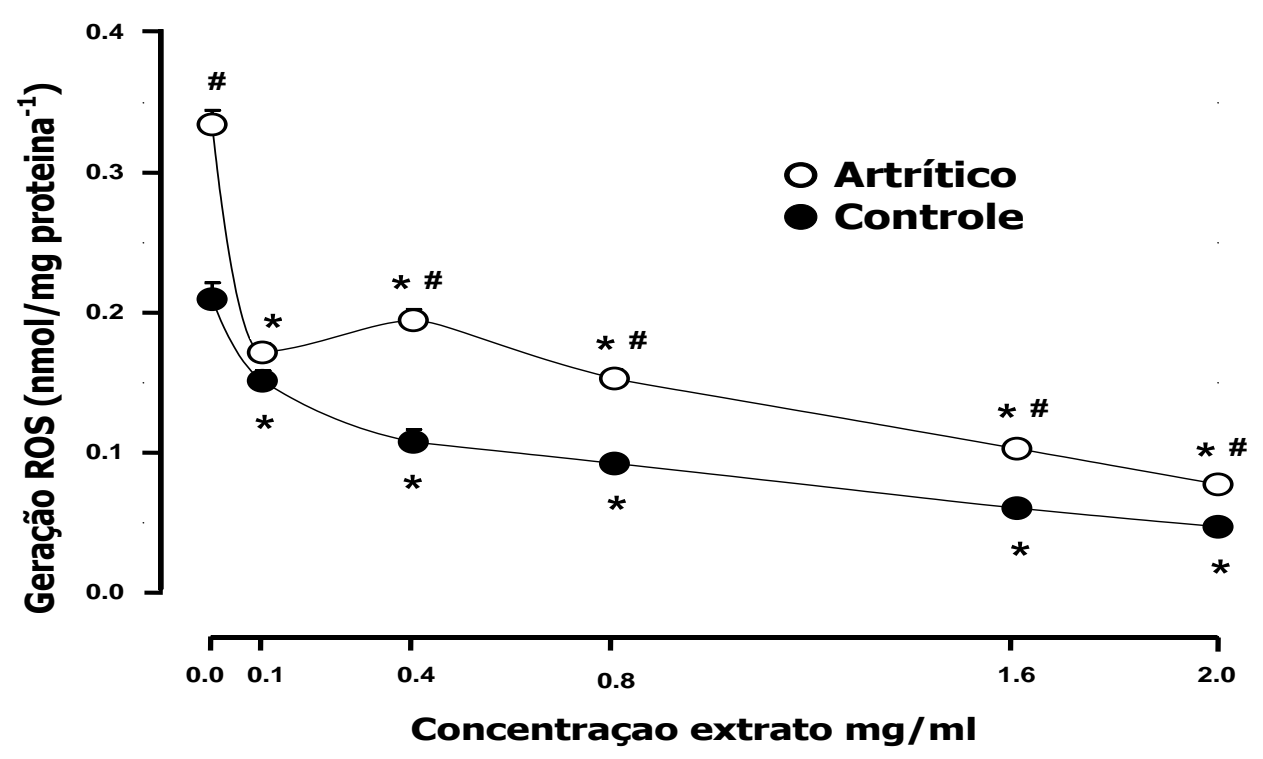

Figura 1. Produção de espécies reativas de oxigênio (ROS) em mitocôndrias isoladas de fígado de ratos $(n=4)(p<0,05)$.\# Diferença entre controle e artrítico nas mesmas condições.* Diferem significativamente $(p<0,05)$ em relação à mesma condição sem tratamento.

Universidade Estadual de Londrina- Rodovia Celso Garcia Cid, Pr445, Km 380 - Campus Universitário Caixa Postal 10.011 CEP 86057-970Centro de Ciências Exatas - Departamento de Bioquímica e 


\section{SIMPÓSIO DE BIOQUÍMICA E BIOTECNOLOGIA}

05 a 07 de agosto de 2015, Londrina - PR

\section{VSIMBBTEC}

Londrina 2015

Estudos prévios realizados em nosso laboratório têm demonstrado um aumento do dano oxidativo no fígado de ratos com artrite induzida por adjuvante (Comar et al., 2013). Os resultados obtidos neste estudo sugerem que, pelo menos em parte, o extrato do chá verde age atenuando a geração de ROS nas mitocôndrias, o que pode levar a uma redução dos danos oxidativos nesse órgão.

\section{CONCLUSÕES}

O extrato de chá verde diminuiu a geração de ROS nas mitocôndrias de fígado de ratos. Estes resultados sugerem uma proteção antioxidante do chá verde, a qual se torna especialmente benéfica em estados patológicos como a artrite.

Agência de Fomento: Capes.

\section{REFERÊNCIAS}

BENDELE, A.; MCCOMB, J.; GOULD, T.; MCABEE, T. SENNELLO, G.; CHLIPALA, E. G. U. Y .M. Animal models of arthritis: relevance to human disease.ToxicoPathol, v. 27, n. 1, p. 134-42, 1999.

COMAR, J. F., SÁ-NAKANISHI, A. B. DE, OLIVEIRA, A. J. DE, WENDT, M. M. N., AMADO, C. A. B., ISHII-IWAMOTO, E. L., PERALTA, R. M., \& BRACHT, A. Oxidative state of the liver of rats with adjuvant-induced arthritis. Free Radical Biology and Medicine, n. 58, p. 144-153, 2013.

GABRIEL, S. E.; MICHAUD, K. Epidemiological studies in incidence, prevalence, mortality, and comorbidity of the rheumatic diseases. Arthritis Res Ther, v. 11, n. 3, p. 229-245, 2009.

HUSAIN, S. R., CILLARD, J., CILLARD, P. Phytochemistry, n.26, p. 2489, 1987.

LOWRY, O. H.; ROSEBROUGH, N. J.; LEWIS, F.; RANDALL, R. J. Protein measurement with the Folin phenol reagent. J BiolChem, v. 193, n. 1, p. 265-275, 1951.

PEARSON, C. M. WOOD, F. D. Studies of arthritis and other lesions induced in rats by the injection of mycobacterial adjuvant. Am J Pathol, v. 42, n. 1, p. 73-95, 1963.

RIETVELD, A.; WISEMAN, S. Antioxidant effect s of tea: evidence from human clinical trials. J Nutr, v. 133, n. 10, p. 3275-84, 2003.

SENNA, E. D.; DE BARROS, A. L.; SILVA, E. O.; COSTA, I. F.; PEREIRA, L. V. B.; CICONELLI, R. M.; FERRAZ, M. B. Prevalence of rheumatic diseases in Brazil: a study using the COPCORD approach. J Rheumatol, v. 31, p. 594-597, 2004.

SZEKANECZ, Z.; HALLORAN, M. M.; VOLIN, M. V.; WOODS, J. M.; STRIETER, R.M.; KENNETH, H. G. 3RD.; KUNKEL, S.L.; BURDICK, M.D.; KOCH, A. E. Temporal expression of inflammatory cytokines and chemokines in rat adjuvantinduced arthritis. Arthritis Rheum, v. 43, n. 6, p. 1266-1277, 2000.

ZACCAGNINO, P., SALTARELLA, M., D'ORIA, S., CORCELLI,A., SAPONETTI, M. S., LORUSSO, M.N-arachidonylglycine causes ROS production and cytochrome c release in liver mitochondria. FreeRadBiolMed, n. 47, p. 585-592, 2009.

Universidade Estadual de Londrina- Rodovia Celso Garcia Cid, Pr445, Km 380 - Campus Universitário Caixa Postal 10.011 CEP 86057-970Centro de Ciências Exatas - Departamento de Bioquímica e BiotecnologiaFone +55 (43) 3371.4270 - biq@uel.br 